\title{
Impresi e-Payment dan Niat Berperilaku Baru Bagi Pemanfaatan Inklusi Keuangan Digital UMK
}

\author{
e-Payment Impression and New Behavioral Intention toward the \\ Utilization of Digital Financial Inclusion MSEs
}

Oleh:

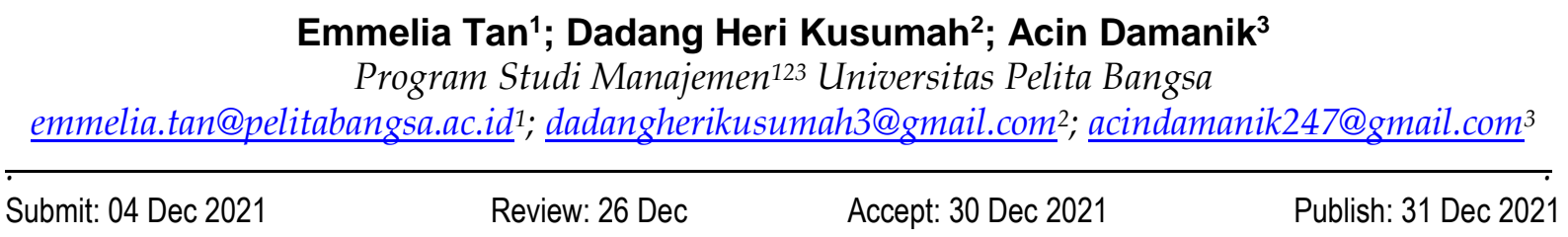

\begin{abstract}
ABSTRAK
Bagaimana impresi penggunaan e-payment dan niat berperilaku baru menggunakan e-payment di masa new normal pada usaha mikro dan kecil?. Penelitian ini bertujuan menguji model penelitian yang menjelaskan impresi e-payment dan niat berperilaku baru terhadap pemanfaatan inklusi keuangan digital UMK. Sampel penelitian adalah usaha mikro dan kecil di Cikarang, sebanyak 81 responden pemilik UMK. Data penelitian diolah dan dianalisa menggunakan SEM-PLS dengan aplikasi WrapPLS 7.0. Hasil penelitian mengemukakan bahwa impresi e-payment berpengaruh positif signifikan terhadap niat berperilaku dan inklusi keuangan. Niat berperilaku baru penggunaan e-payment berpengaruh signifikan positif pada inklusi keuangan UMK. Niat berperilaku baru memediasi parsial hubungan impresi e-payment terhadap inklusi keuangan digital UMK. Niat perperilaku baru penggunaan Fintech berkontribusi lebih besar dibandingkan impresi penggunaan e-payment pada transaksi keuangan digital UMK.
\end{abstract}

Kata kunci:

e-payment; Fintech; minat perilaku baru; pemanfaatan inklusi keuangan digital; Usaha Mikro Kecil

\begin{abstract}
How are the impressions of using e-payments and new behavior intentions using e-payments in the new normal for micro and small businesses? This study aims to examine a research model that explains the impression of e-payments and new behavioral intentions toward utilization of digital financial inclusion MSEs. The research sample is micro and small businesses in Cikarang, with 81 respondents who own MSEs. The research data was processed and analyzed using SEM-PLS with the WrapPLS 7.0 application. The results showed that the impression of e-payment had a significant positive effect on behavioral intentions and financial inclusion. The new behavioral intention to use e-payments has a significant positive effect on MSEs' financial inclusion. New behavioral intentions partially mediate the impression of e-payment on digital financial inclusion of MSEs. The new behavioral intention to use Fintech contributes more than the impression of using e-payments in MSE digital financial transactions.
\end{abstract}

Keywords:

e-payment; Fintech; new behavioral intention; utilization of digital financial inclusion; MSEs 


\section{PENDAHULUAN}

Peningkatan inklusi keuangan merupakan salah satu jalan penting dalam mencapai beberapa tujuan pembangunan berkelanjutan dalam program global lembaga PBB dan Bank Dunia. Demikian juga, melalui G20 Global Partnership for Financial Inclusion, tahun 2016, pemerintah negara G20 telah berkomitmen untuk mendorong inklusi keuangan dengan pendekatan digital. Teknologi digital dipercaya dan dianggap efektif meningkatkan inklusi keuangan global dengan meingkatkan akses serta penggunaan produk dan layanan keuangan lebih baik, diantaranya mobile money account, mobile payment, e-money dan lainnya. Di Indonesia, Bank Indonesia menjelaskan kerangka Inklusi Keuangan Digital meliputi Inklusi layanan keuangan digital (go branchless), Proteksi konsumen, stabilitas dan integritas. Tahun 2020, OJK meluncurkan Grup Inovasi Keuangan Digital, memfasilitasi Fintech berinovasi dalam produk dan layanan keuangan. Salah satu target penting OJK ialah pemanfaatan Fintech mendukung inklusi keuangan digital UMKM.

Di masa Covid-19 yang masih belum berakhir dan pemerintah Indonesia sudah menyatakan kita perlu menyesuaikan hidup berdampingan dengan varian Covid-19, sektor bisnis, terutama usaha mikro dan kecil, mau tidak mau perlu menyesuaikan kebiasaan baru dengan kondisi pandemi Covid-19. Digitalisasi transaksi keuangan UMKM sebelum pandemi Covid-19 masih terbatas secara umum di negara G20 kurang dari 50\% (OECD, 2021). Survei OECD (2021) mengamati UMKM yang sudah menggunakan transaksi digital sebelum pandemi akan semakin meningkatkan transaksi bisnis dan keuangan digital dan diketahui juga semakin besar omzet UMKM semakin tinggi penggunaan bisnis digital. Secara umum, sektor yang lebih banyak menggunakan bisnis dan keuangan digital yaitu sektor jasa, akomodasi, kuliner, dan ICT. OECD (2021) mengamati peningkatan transaksi bisnis dan keuangan digital berdasarkan dari karakteristik usaha dan personal pemilik UMKM.

Inklusi keuangan digital, menurut Feng et al., (2019) adalah model penting untuk mewujudkan inklusi keuangan yang lebih murah, menjangkau area populasi lebih luas tanpa membedakan individu dan sistem keuangan yang berkelanjutan. Dijelaskan ada tiga dimensi pokok dalam indikator inklusi keuangan digital adalah luasnya cakupan, frekuensi penggunaan, dan tingkat digitalisasi produk dan layanan keuagan digital. Hubungan inklusi keuangan tradisional dan inklusi keuangan digital saling melengkapi dan mendorong secara positif. Kemajuan perkembangan sistem pemabayaran elektronik (e-payment) menjadi peluang besar bagi negara-negara di dunia mendorong inklusi keuangan dengan adopsi metode pembayaran mobile(Lutfi et al., 2021). Penetrasi mobile phone yang tinggi dan lebih dari $50 \%$ populasi Indonesia adalah pengguna internet merupakan kunci pemberdayaan dan peluang bagi inklusi keuangan digital.

Beberapa teori dipakai menjelaskan untuk menentukan penerimaan mobile payment pada pengguna seperti pemilik UMK. Dalam Technology Acceptance Model (TAM), niat berperilaku (behavioral intention) penggunaan Fintech bisa ditentukan oleh faktor persepsi manfaat (perceived usefuness), persepsi kemudahan ( perceived ease of use) Fintech (Lutfi et al., 2021; Wiyono \& Kirana, 2020). Selain itu toleransi atas kendala penggunaan Fintech atau dapat dikatakan sebagai persepsi kontrol perilaku dapat berkontribusi pada niat berperilaku penggunaan Fintech (Ayudya \& Wibowo, 2018; Qurniawati, 2020; Wiyono \& Kirana, 2020).

Faktor situasional yang mendukung penggunaan Fintech dan motivasi intrinsik dapat mempengaruhi penggunaan Fintech (Wang et al., 2019). Pada masa pandemi kebijakan pemerintah dalam new normal mempengaruhi perilaku saat ini dalam menggunakan Fintech atau disebut minat 
perilaku baru (Wiyono \& Kirana, 2021). Sejak pandemi terjadi peningkatan transaksi e-money secara signifikan dari pengguna Fintech sebelum pandemi dan pengguna baru Fintech sejak pandemi. Di masa pandemi, transaksi bisnis perlu menggunakan keuangan digital, merasakan pengalaman menggunakan dan impresi Fintech akan membentuk minat perilaku penggunaan (Le, 2021).

Penelitian ini bertujuan memprediksi pengaruh impresi Fintech e-payment dan minat perilaku baru apakah mempengaruhi penggunaan Fintech secara berkelanjutan dinyatakan pada pemanfaatan inklusi keuangan digital. Literatur ilmiah yang membahas pemanfaatan inklusi keuangan digital bagi UMKM saat ini masih terbatas, paling sering ditemukan dalam bentuk working paper dari lembaga seperti OJK, ADB, OECD, dan world bank. Penelitian ini diharapkan mengisi keterbatasan penelitian inklusi keuangan digital bagi usaha mikro dan kecil.

Di Indonesia, penelitian empiris dan deskripsi kualitatif/kuantitatif menghubungkan Fintech pada inklusi keuangan. Penelitian empiris oleh Nurohman et al., (2021) membahas bagaimana pengaruh pengetahuan produk Fintech dan manajemen risiko terhadap inklusi keuangan dan kinerja UMKM. Penelitian ini menggunakan indikator inklusi keuangan konvensional seperti penggunaan akun bank, penggunaan produk asuransi dan pinjaman bank berdasarkan pada referensi OJK (2017). Penelitian lain dengan pendekatan deskriptif kualitatif oleh Shofawati (2019) menjelaskan peran keuangan digital dengan menciptakan akses pendanaan lebih mudah bagi UMKM dapat memperkuat inklusi keuangan. Dengan pendekatan teknik yang sama Marginingsih (2021) menjelaskan Fintech lending dalam inklusi keuangan disertakan dengan data-data ekonomi Indonesia, dimana penelitian ini menyimpulkan Fintech lending berpengaruh positif pada inklusi keuangan di masa pandemi.
Penelitian kuantitatif sebelumnya oleh Rusdianasari (2018) menggunakan data perkembangan Fintech berupa ATM dan emoney diintegrasikan dalam inklusi keuangan menemukan peran fintech belum maksimal pada inklusi keuangan dan stabilitas keuangan. Dikarenakan masih belum merata adaptasi Fintech bagi masyarakat lapisan bawah misalnya usaha mikro dan kecil yang mendominasi transaksi ekonomi.

Penelitian terdahulu di Indonesia terkait minat perilaku (behavioral intention) menggunakan Fintech pada UMKM. Diantaranya, Wiyono \& Kirana (2020) efek impresi Fintech dari segi manfaat dan kemudahan dimediasi oleh permasalahan penggunaan Fintech terhadap Niat berperilaku pemilik UMKM. Penelitian lain yang dikaitkan dengan masa new normal dalam studi empiris Wiyono \& Kirana, (2021) menemukan pelaku UMKM keadaan kebiasaan baru masa pandemi berpengaruh positif perilaku baru penggunaan Fintech. Penelitian adopsi Fintech pada user individu Fintech oleh Setiawan et al., (2021) mempertimbangkan diantaranya persepsi kegunaan, persepsi manfaat, image brand, dan sikap pengguna. Penelitian lain yang khusus meneliti intensi perilaku dalam menggunakan emoney oleh Ayudya \& Wibowo, (2018) dengan teori Planned Behavior menemukan sikap perilaku dan persepsi perilaku kontrol berpengaruh positif pada minat menggunakan e-money. Penelitian selanjutnya (Ardianto \& Azizah, 2021) terkait e-money atau dompet digital dengan teori TAM mendukung bahwa persepsi kegunaan dan kemudahan penggunaan berpengaruh terhadap minat penggunaan e-money.

Pemanfaatan inklusi keuangan digital dapat dipengaruhi oleh faktor demografi responden. Penelitian ini menambah variabel kontrol dari data demografi yaitu usia pemilik UMK, omzet dan lama operasi usaha (Coffie et al., 2020). Pemilik usaha dengan usia lebih muda, lebih melek keuangan digital dibandingkan pemilik usaha berusia tua diatas 40 tahun keatas 
atau dengan kata lain kemampuan adopsi Fintech dapat dipengaruhi oleh usia pemilik UMK (Kusumaningtyas \& Suwarto, 2015; Coffie et al., 2020). Semakin besar omzet usaha UMK semakin tinggi penggunaan produk dan layanan keuangan digital (OECD, 2021). Usaha UMK dimana sebelum pandemi sudah terbiasa dengan layanan keuangan digital, pada masa pandemi akan semakin meningkatkan transaksi penggunaan keuangan digital e-payment, sehingga lama usaha dianggap mempengaruhi inklusi keuangan digital dalam model penelitian ini. Demikian juga, usaha UMK yang sudah lama beroperasi dan tidak menggunakan Fintech e-payment akan lebih susah mengadopsi Fintech.
Berdasarkan penjelasan latar belakang diatas, maka penelitian ini menggambarkan kerangka pemikiran pada Gambar 1 maka:

Hipotesis 1: Impresi Fintech (epayment) mempunyai efek positif pada Intensi perilaku baru.

Hipotesis 2 : Niat berperilaku baru penggunaan e-payment memiliki efek positif pada pemanfaatan Inklusi keuangan digital.

Hipotesis 3 : Impresi Fintech (epayment) mempunyai efek positif pada pemanfaatan Inklusi keuangan digital

Hipotesis 4 : Niat berperilaku baru memediasi Impresi Fintech (e-payment) terhadap pemanfaatan Inklusi keuangan digital UMK.

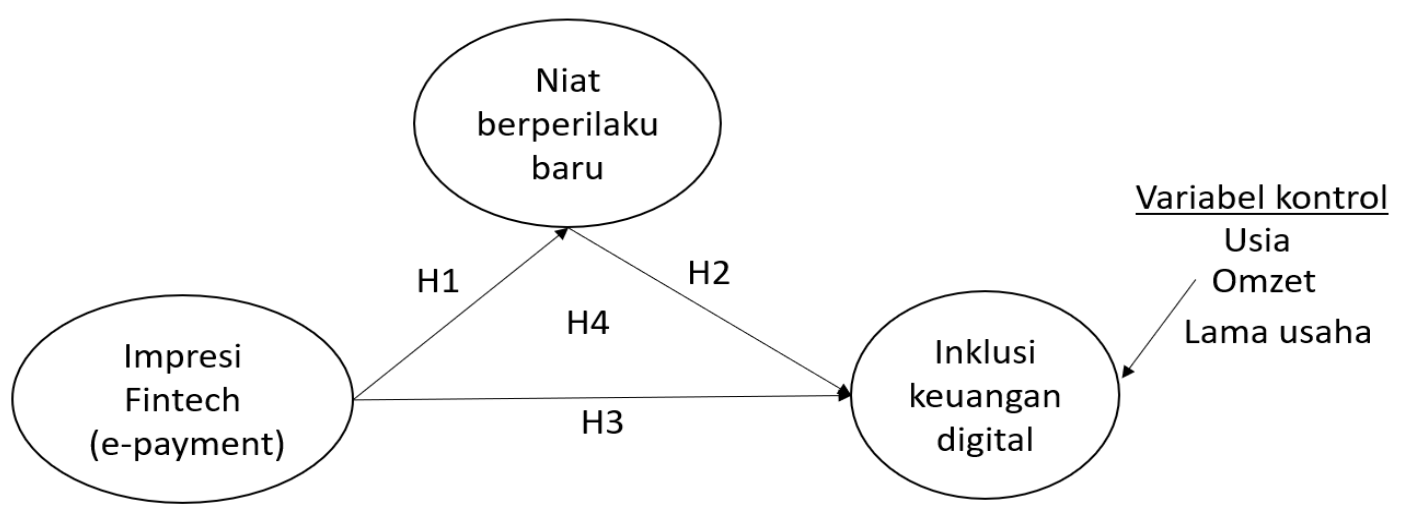

Gambar 1. Kerangka pemikiran \& hipotesis

\section{METODE PENELITIAN}

Populasi penelitian adalah usaha mikro dan kecil di Cikarang, Bekasi baik yang menggunakan e-payment dan belum menggunakan e-payment dalam transaksi usaha. Pengukuran variabel penelitian dilakukan dengan pilihan 5 skala Likert. Variabel impresi e-payment ada sebanyak 3 indikator pertanyaan (Wiyono \& Kirana, 2020). Variabel minat perilaku baru memiliki 2 indikator pertanyaan yang merujuk dari penelitian sebelumnya Wiyono et al., (2021). Variabel Pemanfaatan Inklusi keuangan digital sebanyak 3 indikator sesuai referensi dari Pambudianti et al., (2020a) dan Senyo \& Osabutey, (2020).
Metode penelitian dengan pendekatan kualitatif yang bertujuan menganalisis dampak impresi dan minat perilaku baru pada e-payment terhadap pemanfaatan inklusi keuangan digital pada Usaha Mikro dan Kecil, sekaligus menguji efek mediasi dari minat perilaku baru. Analisa data menggunakan pendekatan SEM-PLS dengan bantuan aplikasi WrapPLS 7.0.

Langkah prediksi hipotesis dalam SEM-PLS meliputi pengujian outer model (model pengukuran) dan inner model (model struktural). Pengujian model pengukuran untuk validitas menggunakan outer loading dan AVE (average variance extracted) sebagai bentuk uji validitas dimana batas diterima 0,7 outer loading dan AVE sebesar 0,5 untuk model pengukuran 
reflektif. Pengujian reliabilitas dengan Cronbach's alpha dan Composite reliability dengan batas minimum diterima 0,7. Pengujian model struktural dengan estimasi koefisien jalur, effect size, $Q$-squared dan koefisien determinasi $R$-squared.

\section{HASIL PENELITIAN}

\section{Responden}

Sampel responden penelitian adalah pengusaha mikro dan kecil di Cikarang Utara, Bekasi, Jawa Barat, mayoritas responden adalah pedagang, pemilik toko, dan usaha kuliner. Pengambilan data kuesioner dilakukan secara langsung dan sebagian online kepada pemilik usaha mikro dan kecil dari periode bulan Maret Mei 2021. Data demografi responden dijelaskan dalam tabel 1.

\section{Pengujian Outer Model}

Hasil pengujian outer model untuk evaluasi validitas dan reliabilitas dapat dilihat pada tabel 2. Pengujian validitas menunjukkan seluruh indikator pada semua variabel penelitian telah valid dengan outer loading masing-masing diatas 0,7 dan AVE diatas 0,5. Tabel 3 juga menjelaskan validitas diskriminan, terlihat hasil akar AVE dari setiap variabel memiliki nilai korelasi lebih tinggi daripada korelasi antar variabel. Kemudian, hasil uji reliabilitas pada ketiga variabel penelitian menunjukkan sudah memenuhi batas diterima yaitu diatas 0,7 untuk Cronbach's alpha sebagai batas bawah dan Composite reliability sebagai batas atas.

Tabel 1. Responden

\begin{tabular}{|c|c|c|}
\hline Karakteristik & Jumlah & Persentase $(\%)$ \\
\hline \multicolumn{3}{|l|}{ Jenis Kelamin } \\
\hline - Perempuan & 38 & 46,91 \\
\hline - Laki-laki & 43 & 53,09 \\
\hline \multicolumn{3}{|l|}{ Usia } \\
\hline - $\quad 15-25$ tahun & 30 & 37,04 \\
\hline$-\quad 26-35$ tahun & 26 & 32,10 \\
\hline - $\quad 36-45$ tahun & 16 & 19,75 \\
\hline - $\quad 46-55$ tahun & 9 & 11,11 \\
\hline \multicolumn{3}{|l|}{ Lama usaha } \\
\hline$-\quad<1$ tahun & 8 & 9,88 \\
\hline - $1-5$ tahun & 50 & 61,73 \\
\hline - 6-10 tahun & 10 & 12,35 \\
\hline - $\quad 11-15$ tahun & 9 & 11,11 \\
\hline$-\quad>15$ tahun & 4 & 4,94 \\
\hline \multicolumn{3}{|l|}{ Jumlah karyawan } \\
\hline - Tidak memiliki karyawan & 27 & 33,33 \\
\hline - $\quad 1-5$ orang & 54 & 66,67 \\
\hline \multicolumn{3}{|l|}{ Omzet per tahun } \\
\hline$-\quad<300$ juta & 62 & 76,54 \\
\hline$-\quad 300-500$ juta & 19 & 23,46 \\
\hline \multicolumn{3}{|l|}{$\begin{array}{l}\text { Menerima pembayaran digital/e- } \\
\text { payment }\end{array}$} \\
\hline - Ya & 45 & 55,56 \\
\hline - $\quad$ Tidak/Belum & 36 & 44,44 \\
\hline
\end{tabular}


Tabel 2. Outer Model

\begin{tabular}{|c|c|c|c|c|c|}
\hline Variabel/Indikator & $\begin{array}{c}\text { Outer } \\
\text { Loading }\end{array}$ & AVE & $\begin{array}{l}\text { Cronbach } \\
\text { Alpha }\end{array}$ & $\begin{array}{l}\text { Composite } \\
\text { Reliability }\end{array}$ & Kesimpulan \\
\hline Impresi e-payment $(\mathrm{X} 1)$ & & 0,941 & 0,968 & 0,979 & Reliabel \\
\hline $\begin{array}{l}\text { X1.1. Kemudahan transaksi e- } \\
\text { payment }\end{array}$ & 0,970 & & & & Valid \\
\hline $\begin{array}{l}\text { X1.2. Manfaat penggunaan e- } \\
\text { payment }\end{array}$ & 0,965 & & & & Valid \\
\hline $\begin{array}{l}\text { X1.3.Toleransi kendala } \\
\text { penggunaan e-payment }\end{array}$ & 0,975 & & & & Valid \\
\hline Minat perilaku baru (X2) & & 0,943 & 0,940 & 0,971 & Reliabel \\
\hline $\begin{array}{l}\text { X2.1. Dalam era kenormalan baru, } \\
\text { penggunaan e-payment } \\
\text { sangat dibutuhkan dalam } \\
\text { transaksi UMK }\end{array}$ & 0,971 & & & & Valid \\
\hline $\begin{array}{l}\text { X2.2. Supaya tetap bertahan UMK } \\
\text { harus adaptasi dalam era } \\
\text { kenormalan baru. }\end{array}$ & 0,971 & & & & Valid \\
\hline Inklusi keuangan digital (Y) & & 0,623 & 0,697 & 0,832 & Reliabel \\
\hline $\begin{array}{l}\text { Y.1. Akses dan frekuensi } \\
\text { penggunaan e-payment } \\
\text { secara berkelanjutan }\end{array}$ & 0,775 & & & & Valid \\
\hline $\begin{array}{l}\text { Y.2. Pemanfaatan ketersediaan dan } \\
\text { kemudahan fasilitas internet } \\
\text { dalam transaksi keuangan } \\
\text { digital }\end{array}$ & 0,771 & & & & Valid \\
\hline $\begin{array}{l}\text { Y.3. Kepemilikan produk keuangan } \\
\text { Bank } \\
\text { konvensional/digital/Fintech } \\
\text { dalam jangka panjang }\end{array}$ & 0,822 & & & & Valid \\
\hline
\end{tabular}

Tabel 3. Hasil akar AVE

\begin{tabular}{cccc}
\hline & $X 1$ & $X 2$ & $Y$ \\
\hline$X 1$ & 0,970 & & \\
X2 & 0,204 & 0,971 & \\
Y & 0,379 & 0,620 & 0,790 \\
\hline
\end{tabular}

\section{Pengujian Model Struktural}

Terlebih dahulu menguji model fit dan model indeks kualitas yang dijelaskan pada tabel 4. Dapat dikatakan model penelitian ini, dapat diterima dengan baik. Selanjutnya melihat pengaruh antar variabel dalam hipotesis pada tabel 5 . Hipotesis 1 diterima, karena terdapat pengaruh positif signifikan Impresi epayment (X1) terhadap minat perilaku baru (X2) pada UMK dengan koefisien sebesar 0,273 ( $p$-value 0,005). Pada direct effect, minat perilaku baru (X2) berpengaruh positif signifikan pada Pemanfaatan Inklusi keuangan digital $(\mathrm{Y})$ koefisien sebesar 0,526 ( $\mathrm{p}$-value $<0,001$ ), sehingga hipotesis 2 diterima. Hipotesis 3 pengaruh Impresi e-payment Fintech (X1) terhadap Pemanfaatan Inklusi keuangan digital (Y) dilihat pada total effect, ditemukan positif signifikan dengan koefisien sebesar 0,350 ( $p$-value $<0,001$ ), dengan demikian Hipotesis 3 diterima. 
Uji mediasi Hipotesis 4 dapat diperbandingkan pada tabel 5 melalui direct effect $\mathrm{X} 1 \rightarrow \mathrm{Y}$ koefisien jalur sebesar 0,207 ( $\mathrm{p}$-value 0,026 ) positif signifikan dan indirect effect $\mathrm{X} 1 \rightarrow \mathrm{X} 2 \rightarrow \mathrm{Y}$ koefisien sebesar 0,144 (p-value 0,031) positif signifikan sehingga mediasi dikategorikan komplementer (Sholihin \& Dwi, 2020). Sebagai tambahan, koefisien direct effect $\mathrm{X} 1 \rightarrow \mathrm{Y}$ sebelum ditambahkan variabel mediasi sebesar 0,420 ( $\mathrm{p}$-value $<0,01$ ) dan setelah dimasukkan variabel mediasi koefisien menjadi 0,207 (p-value 0,026), sehingga dapat disimpulkan variabel Minat perilaku baru (X2) memediasi parsial hubungan variabel Impresi epayment (X1) terhadap Pemanfaatan inklusi keuangan digital $(\mathrm{Y})$, hipotesis 4 diterima.

Pada tabel 5, koefisien adjusted $\mathrm{R}^{2}$ menjelaskan sebesar 44,5\% variabel endogen Pemanfaatan Inklusi keuangan digital UMK dapat diprediksi variabel eksogen secara bersama-sama yaitu Impresi e-payment Fintech dan Minat perilaku baru. Selanjutnya effect size $\left(\mathrm{f}^{2}\right)$, pada tabel direct effect untuk melihat tingkat prediksi masing-masing variabel eksogen terhadap variabel endogen dalam model penelitian. Effect size dapat dikategorikan yaitu lemah $(0,02-0,15)$, medium $(0,15-0,35)$ dan besar $(>0,35)$ (Sholihin \& Dwi, 2020). Sehingga, dapat dijelaskan variabel Minat perilaku baru (X2) mempunyai nilai prediksi medium dengan effect size 0,326. Sedangkan, Impresi e-payment Fintech (X1) memiliki nilai prediksi dengan effect size lemah sebesar 0,082 terhadap Pemanfaatan Inklusi keuangan digital $(\mathrm{Y})$.

Ilustrasi world cloud dari tanggapan responden tentang impresi e-payment dari sisi manfaat terlihat pada Gambar 3. Beragam jawaban dari reponden UMK dengan pertanyaan impresi kelebihan epayment adalah lebih efisien, lebih praktis, lebih simpel, lebih efektif, hemat waktu, lebih mudah bertransaksi, memudahkan konsumen, pemilik UMK tidak khawatir menerima uang palsu, dan tidak perlu mencari uang kembalian. Impresi terhadap e-payment terkait permasalahan dalam penggunaan yaitu jaringan error, atau apabila sinyal bermasalah dan koneksi internet tidak baik.

Variabel kontrol yang mempengaruhi pemanfaatan inklusi keuangan digital dari usia pemilik, omzet UMK dan lamanya usaha beroperasi menunjukkan hasil tidak signifikan dalam model penelitian.

Tabel 4. Uji model Goodness of fit (Gof)

\begin{tabular}{cccc}
\hline Gof & Kriteria & Hasil & Kesimpulan \\
\hline APC & $\mathrm{p}<0,05$ & 0,$219 ; \mathrm{p}$-value 0,010 & Model fit \\
ARS & $\mathrm{p}<0,05$ & 0,$277 ; \mathrm{p}$-value 0,002 & Model fit \\
AARS & $\mathrm{p}<0,05$ & 0,$254 ;$ p-value 0,004 & Model fit \\
AVIF & diterima $<=5$, ideal $<=3,3$ & 1,252 & Ideal \\
AFVIF & diterima $<5$, ideal $<=3,3$ & 1,473 & Ideal \\
GoF & small $>0,1 ;$ medium $>0,25 ;$ large $>0,36$ & 0,505 & Large \\
SPR & diterima $>0,7 ;$ ideal $=1$ & 1,000 & Ideal \\
RSCR & diterima $>0,9 ;$ ideal $=1$ & 1,000 & Ideal \\
SSR & diterima $>0,7$ & 1,000 & Diterima \\
NLBCDR & diterima $>0,7$ & 1,000 & Diterima \\
\hline
\end{tabular}




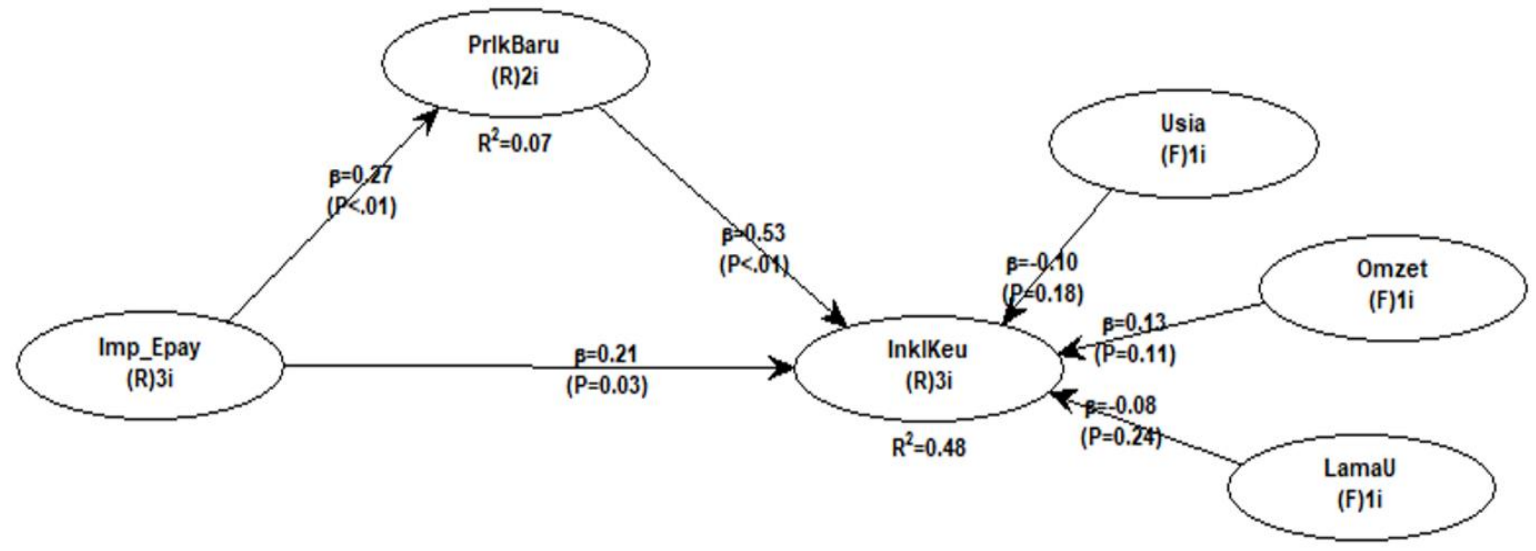

Gambar 2. Model analisis jalur

Tabel 5. Pengujian hipotesis

\begin{tabular}{lcccccc}
\hline Jalur deskripsi & Koefisien jalur & p-value & Effect size $\left(\mathrm{f}^{2}\right)$ & S.E. & Adj. $\mathrm{R}^{2}$ & $\mathrm{Q}^{2}$ \\
\hline Total Effect & $0,350^{* * *}$ & $<0,001$ & 0,139 & 0,101 & & \\
$\mathrm{H} 3: \mathrm{X} 1 \rightarrow \mathrm{Y}=\mathrm{c}$ & & & & & 0,445 & 0,489 \\
\hline Direct effect & $0,207^{*}$ & 0,026 & 0,082 & 0,105 & & \\
$\mathrm{X} 1 \rightarrow \mathrm{Y}=\mathrm{c}^{\prime}$ & $0,273^{* *}$ & 0,005 & 0,075 & 0,103 & & \\
$\mathrm{H} 1: \mathrm{X} 1 \rightarrow \mathrm{X} 2=\mathrm{a}$ & $0,526^{* * *}$ & $<0,001$ & 0,326 & 0,095 & & \\
$\mathrm{H} 2: \mathrm{X} 2 \rightarrow \mathrm{Y}=\mathrm{b}$ & & & & & & \\
\hline Indirect effects (2 segments) & $0,144^{*}$ & 0,031 & 0,057 & 0,076 & & \\
$\mathrm{H} 4: \mathrm{X} 1 \rightarrow \mathrm{X} 2 \rightarrow \mathrm{Y}=\mathrm{a}^{*} \mathrm{~b}$ & & & & &
\end{tabular}

${ }^{* * *} \mathrm{p}<0,001 ;{ }^{* *} \mathrm{p}<0,01 ;{ }^{*} \mathrm{p}<0,05$

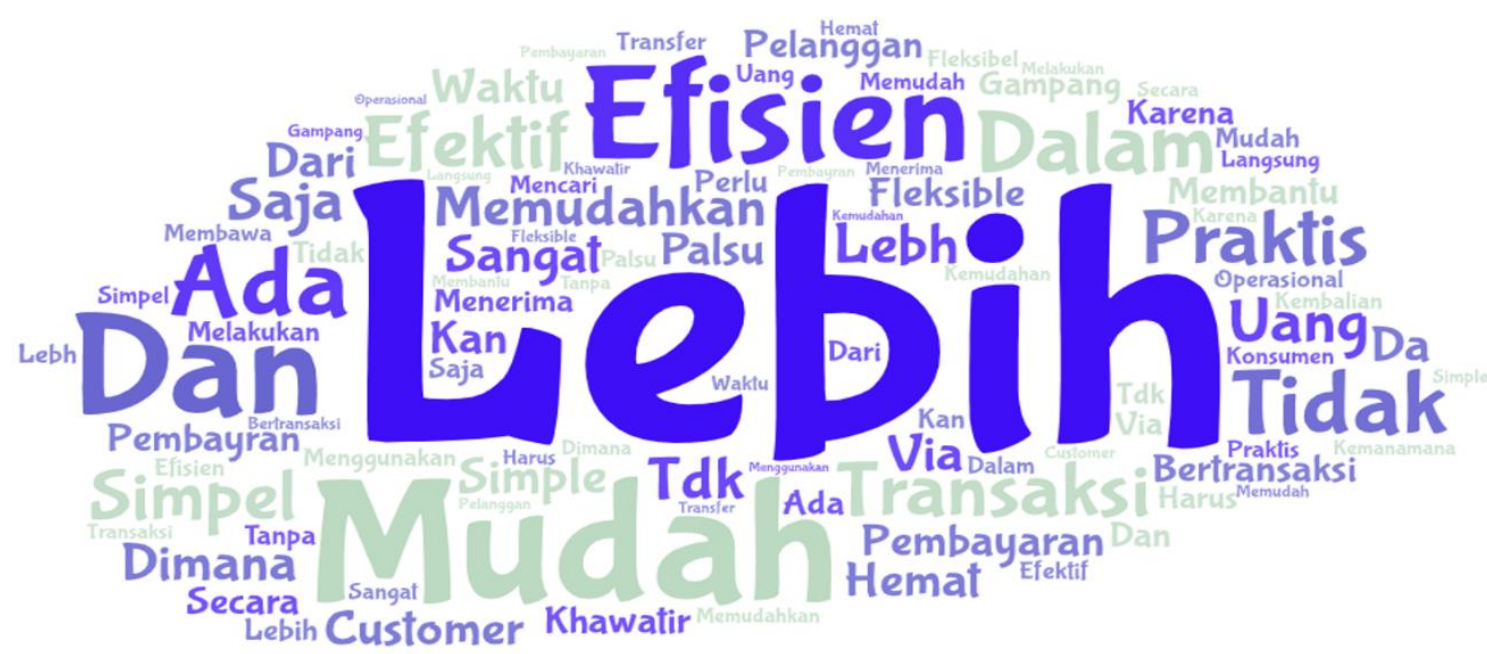

Gambar 3. Impresi sisi positif e-payment dari segi manfaat

\footnotetext{
170 "Impresi e-Payment dan Niat Berperilaku Baru Bagi Pemanfaatan Inklusi Keuangan Digital UMK..."
} 


\section{PEMBAHASAN}

Semakin baik impresi Fintech epayment meningkatkan niat berperilaku menggunakan Fintech bagi pemilik UMK. Hasil penelitian ini memperkuat penelitian terdahulu (Permadi, L. A., \& Rinuastuti, 2020; Kumala et al., 2020; Ardianto \& Azizah, 2021; Lutfi et al., 2021) dimana impresi Fintech melalui kemudahan penggunaan dan manfaat penggunaan berpengaruh positif pada niat berperilaku penggunaan Fintech. Demikian juga persepsi kontrol perilaku dalam toleransi kendala penggunaan Fintech oleh UMK mempengaruhi kepada niat perilaku (Qurniawati, 2020). Penelitian ini juga mendukung penemuan dari penelitian (Wiyono \& Kirana, 2020) yang menyatakan persepsi manfaat Fintech berpengaruh positif pada intensi perilaku dan walaupun ada kendala tidak menurunkan niat perilaku penggunaan Fintech. Kesan positif dari manfaat penggunaan, kemudahan bertransaksi Fintech epayment dan kendala dalam penggunaan yang dapat ditoleransi, meningkatkan niat berperilaku penggunaan Fintech pada masa Covid-19.

Semakin tinggi niat berperilaku baru pemilik UMK akan semakin tinggi pemanfaatan inklusi keuangan digital. Niat berperilaku baru karena dampak pandemi-Covid 19 berperan penting pada peningkatan inklusi keuangan digital UMK terlihat dari effect size paling besar. Hasil penelitian ini sejalan dengan penelitian kuantitatif terdahulu (Al Hashfi et al., 2020). UMK yang memiliki niat perilaku baru penggunaan Fintech epayment, membiasakan diri bertransaksi online menyebabkan semakin inklusif dalam keuangan digital. Hasil penelitian ini memperkuat penelitian oleh Le, (2021), dampak kebijakan social distancing masa pandemi Covid-19 mendorong intensi perilaku baru UMK yang membuat transaksi keuangan digital meningkat. Konsisten dengan penelitian (Shiau et al., 2020) menyatakan dalam penggunaan Fintech yang berkelanjutan tercermin dalam peningkatan inklusi keuangan digital, faktor yang perlu dipertimbangkan motivasi intrinsik pengguna Fintech yang tercermin dalam niat berperilaku penggunaan Fintech.

Semakin baik impresi Fintech epayment akan meningkatkan pemanfaatan inklusi keuangan digital usaha mikro dan kecil. Hasil penelitian ini memperkuatkan pembahasan pada penelitian Siano et al., (2020). Penetrasi mobile banking mendorong inklusi keuangan di negara berkembang. Hal ini sejalan dengan penelitian oleh Shiau et al., (2020) yang menemukan persepsi manfaat dan konfirmasi positif impresi terhadap Fintech mempengaruhi niat penggunaan Fintech secara berkelanjutan. Dengan kata lain, niat menggunakan Fintech secara berkelanjutan menjadikan inklusi keuangan digital meningkat.

Impresi Fintech e-payment yang baik menyebabkan niat berperilaku baru penggunaan Fintech tinggi dan selanjutnya meningkatkan pemanfaatan inklusi keuangan digital UMK. Hasil penelitian ini sejalan dengan penelitian empiris terdahulu oleh (Senyo \& Osabutey, 2020a). Manfaat penggunaan, kemudahan dalam penggunaan dan toleransi kendala penggunaan Fintech e-payment berhubungan positif pada niat berperilaku baru yang pada akhirnya meningkatkan inklusi keuangan digital UMK. Hasil penelitian ini mendukung pembahasan dalam penelitian Le, (2021) dampak lockdown pada masa pandemi melalui kesan pengalaman menggunakan Fintech akan membuat Fintech user mau menggunakan kembali sehingga selanjutnya transaksi keuangan digital meningkat.

Dalam penelitian ini diketahui bahwa usia pemilik UMK, omzet usaha dan lamanya usaha beroperasi tidak mempengaruhi pemanfaatan inklusi keuangan digital usaha mikro dan kecil. Hal ini sejalan dengan hasil penelitian empiris oleh Kusumaningtyas \& Suwarto (2015) dan Al Hashfi et al., (2020) menemukan tidak ada perbedaan dalam 
adopsi ICT bagi UMKM dari sisi usia pemilik. Kemudahan aplikasi membuat penyebaran Fintech payment tinggi tanpa membedakan usia. Akan tetapi, hasil penelitian ini tidak sama dengan Coffie et al., (2020) dan laporan survei OECD (2021), menyimpulkan semakin besar ukuran omzet UMKM mempengaruhi transaksi keuangan digital menjadi semakin tinggi dimana UMK yang berukuran lebih besar lebih cepat adopsi Fintech dengan baik. Dikarenakan reponden penelitian ini mayoritas usaha mikro sekitar $77 \%$ dan berusia muda dibawah 35 tahun sekitar $70 \%$ dan lama usaha mayoritas dibawah 5 tahun dengan prosentasi $70 \%$ sehingga variabel kontrol usia pemilik, omzet usaha dan lamanya usaha tidak signifikan mempengaruhi akses dan penggunaan keuangan digital pada UMK.

\section{KESIMPULAN}

Penerimaan teknologi Fintech epayment dari impresi pengalaman manfaat, kemudahan dan kontrol perilaku terhadap kendala penggunaan Fintech berpengaruh positif pada niat perilaku dan penggunaan Fintech dalam inklusi keuangan digital secara berkelanjutan. Situasional faktor pada masa pandemi yaitu keperluan menggunakan Fintech epayment berperan besar dalam peningkatan transaksi digital bagi usaha mikro dan kecil.

Hasil penilaian kekuatan prediksi model dengan pendekatan teknik PLS pada model penelitian menemukan bahwa kekuatan prediksi Niat berperilaku baru paling besar mempengaruhi pemanfaatan inklusi keuangan digital. Berdasarkan hal ini motivasi intriksik pemilik UMK dalam transaksi Fintech perlu dipertimbangkan dan berpengaruh cukup kuat.

Pemanfaatan inklusi keuangan digital Usaha Mikro dan Kecil dalam penelitian ini tidak dipengaruhi oleh faktor pemilik UMK dari segi usia karena kemudahan aplikasi e-payment bisa diterima semua usia yang bertransaksi. Faktor jenis usaha UMK yaitu omzet atau ukuran usaha dan lama usaha juga tidak membedakan dalam pemanfaatan inklusi keuangan digital UMK. Karena, Fintech model e-payment merupakan model aplikasi Fintech yang simpel dan dapat ditoleransi dengan baik oleh pemilik UMK.

Penelitian ini menambah literatur pemanfaatan inklusi keuangan digital UMK ditentukan dari impresi atau persepsi Fintech user dan niat perilaku baru setelah pandemi. Kedepan, dapat menjadi peluang topik penelitian selanjutnya dengan fondasi teori yang lebih kuat seiring perkembangan literatur Fintech bagi UMK.

\section{DAFTAR PUSTAKA}

Al Hashfi, R. U., Zusryn, A. S., Khoirunnisa, N. L., \& Listyowati, A. R. F. A. (2020). Online Payment, Individual Characteristics, and Digital Financial Inclusion in Oic Countries. Journal of Islamic Monetary Economics and Finance, 6(4), 767-788. https:// doi.org/10.21098/jimf.v6i4.1148

Ardianto, K., \& Azizah, N. (2021). Analisis Minat Penggunaan Dompet Digital Dengan Pendekatan Technology Acceptance Model (TAM) Pada Pengguna di Kota Surabaya. Jurnal Pengembangan Wiraswasta, 23(1), 13. https://doi.org/10.33370/jpw.v23i1.511

Ayudya, A. C., \& Wibowo, A. (2018). The Intention to Use E-Money using Theory of Planned Behavior and Locus of Control. Jurnal Keuangan Dan Perbankan, 22(2), 335-349. https:// doi.org/10.26905/jkdp.v22i2.1691

Coffie, C. P. K., Hongjiang, Z., Mensah, I. A., Kiconco, R., \& Simon, A. E. O. (2020). Determinants of FinTech payment services diffusion by SMEs in Sub-Saharan Africa: evidence from Ghana. Information Technology for Development, 0(0), 1-22. https:// doi.org/10.1080/02681102.2020.1840324 
Feng, G., Jingyi, W., Zhiyun, C., Yongguo, L., Fang, W., \& Aiyong, W. (2019). The Peking University Digital Financial Inclusion Index of China (2011-2018). Institute of Digital Finance, Peking University, April, 1-70.

Kumala, D. C., Pranata, J. W., \& Thio, S. (2020). Pengaruh Perceived Usefulness, Perceived Ease of Use, Trust, Dan Security Terhadap Minat Penggunaan Gopay Pada Generasi X Di Surabaya. Jurnal Manajemen Perhotelan, 6(1), 19-29. https:// doi.org/10.9744/jmp.6.1.19-29

Kusumaningtyas, N., \& Suwarto, D. H. (2015). ICT Adoption, Skill and Use Differences among Small and Medium Enterprises Managers Based on Demographic Factors. Procedia Social and Behavioral Sciences, 169(August 2014), 296-302. https:// doi.org/10.1016/j.sbspro.2015.01.313

Le, M. T. H. (2021). Examining factors that boost intention and loyalty to use Fintech postCOVID-19 lockdown as a new normal behavior. Heliyon, 7(8), e07821. https:// doi.org/10.1016/j.heliyon.2021.e07821

Lutfi, A., Al-Okaily, M., Alshirah, M. H., Alshira'h, A. F., Abutaber, T. A., \& Almarashdah, M. A. (2021). Digital financial inclusion sustainability in Jordanian context. Sustainability (Switzerland), 13(11), 1-13. https:/ / doi.org/10.3390/su13116312

Mahfud Sholihin, Dwi Ratmono. (2020). Analisis SEM-PLS Dengan WarpPLS 7.0 Untuk Hubungan Nonlinier Dalam Penelitian Sosial Dan Bisnis. Yogyakarta: Andi publisher.

Marginingsih, R. (2021). Financial Technology (Fintech) Dalam Inklusi Keuangan Nasional di Masa Pandemi Covid-19. Moneter - Jurnal Akuntansi Dan Keuangan, 8(1), 56-64. https:// doi.org/10.31294/moneter.v8i1.9903

Nurohman, Y. A., Kusuma, M., \& Narulitasari, D. (2021). Fin-Tech, Financial Inclusion, and Sustainability: a Quantitative Approach of Muslims SMEs. International Journal of Islamic Business Ethics, 6(1), 54. https://doi.org/10.30659/ijibe.6.1.54-67

OECD. (2021). G20/OECD-INFE report on navigating the storm: MSMEs' financial and digital competencies in COVID-19 times. www.oecd.org/finance/navigating-the-storm-MSMEsfinancial-and digital- competencies-in-COVID-19-times.htm

Pambudianti, F. F. R., Purwanto, B., \& Maulana, T. N. A. (2020). The implementation of fintech: Efficiency of MSMEs loans distribution and users' financial inclusion index. Jurnal Keuangan Dan Perbankan, 24(1), 68-82. https://doi.org/10.26905/jkdp.v24i1.3218

Permadi, L. A., \& Rinuastuti, B. H. (2020). Pengaruh Persepsi Manfaat dan Kemudahan Penggunaan Terhadap Minat Menggunakan Dompet Digital OVO. Jurnal Sosial Ekonomi Dan Humaniora, 6(1), 54-61. https://doi.org/https://doi.org/10.29303/jseh.v6i1.78

Qurniawati, R. S. (2020). Understanding Halal Food SMEs' behavior intention towards emoney. International Journal of Islamic Business Ethics, 5(2), 113. https:/ / doi.org/10.30659/ijibe.5.2.113-124

Rusdianasari, F. (2018). Kata kunci: Fintech, Inklusi Keuangan, Stabilitas Sistem Keuangan Klasifikasi JEL: G23, E4, E6,. Jurnal Ekonomi Kuantitatif Terapan, 11(2), 244-253. https://ojs.unud.ac.id/index.php/jekt/article/down

Senyo, P. K., \& Osabutey, E. L. C. (2020a). Unearthing antecedents to financial inclusion through FinTech innovations. Technovation, 98(June 2019), 102155. https:// doi.org/10.1016/j.technovation.2020.102155

Senyo, P. K., \& Osabutey, E. L. C. (2020b). Unearthing antecedents to financial inclusion through FinTech innovations. Technovation, 98(June), 102155. https:// doi.org/10.1016/j.technovation.2020.102155 
Setiawan, B., Nugraha, D. P., Irawan, A., Nathan, R. J., \& Zoltan, Z. (2021). User innovativeness and fintech adoption in indonesia. Journal of Open Innovation: Technology, Market, and Complexity, 7(3), 1-18. https://doi.org/10.3390/joitmc7030188

Shiau, W. L., Yuan, Y., Pu, X., Ray, S., \& Chen, C. C. (2020). Understanding fintech continuance: perspectives from self-efficacy and ECT-IS theories. Industrial Management and Data Systems, 120(9), 1659-1689. https:/ / doi.org/10.1108/IMDS-02-2020-0069

Shofawati, A. (2019). The Role of Digital Finance to Strengthen Financial Inclusion and the Growth of SME in Indonesia. KnE Social Sciences, 3(13), 389. https:// doi.org/10.18502/kss.v3i13.4218

Siano, A., Raimi, L., Palazzo, M., \& Panait, M. C. (2020). Mobile banking: An innovative solution for increasing financial inclusion in sub-saharan african countries: Evidence $\begin{array}{llll}\text { from nigeria. } & \text { Sustainability }\end{array}$ https:/ / doi.org/10.3390/su122310130

Wang, Z., GUAN, Z., Hou, F., Li, B., \& Zhou, W. (2019). What determines customers' continuance intention of FinTech? Evidence from YuEbao. Industrial Management and Data Systems, 119(8), 1625-1637. https:/ / doi.org/10.1108/IMDS-01-2019-0011

Wiyono, G., \& Kirana, K. C. (2020). Efek Impresi Fintech Terhadap Perilaku Keuangan Usaha Kecil Menegah (UKM). Jurnal Ilmiah Manajemen Dan Bisnis, 21(1), 69-81. https:// doi.org/10.30596/jimb.v21i1.3889

Wiyono, G., \& Kirana, K. C. (2021). Digital Transformation of SMEs Financial Behavior in the New Normal Era. Jurnal Keuangan Dan Perbankan, 25(1), 191-211. https:// doi.org/10.26905/jkdp.v25i1.4954 